\title{
The theoretical research on the discipline construction of pedagogy
}

\author{
Chen Peixia \\ Department of Education, Pingdingshan Institute of Education, Henan, China \\ peixia656@126.com
}

Keywords: Discipline construction; pedagogy

\begin{abstract}
Education policy research on the problem of contemporary education, history and the social view of macroscopic idea for people to understand the contemporary education problem provides another perspective or way of thinking. This article through the review and summarize the pedagogy direction of the development and theory research, which is a good improvement and help to the education discipline construction.
\end{abstract}

\section{Introduction}

In our country, independent and with the connotation of the modern education about produced in the 19th century and the turn of the 20th century, which is the product of introduces. The end of the 19th century, when the Qing dynasty imperial each provincial counties will run around the industrial school as official legal obligations, which are held in industrial education, an education reform of the most spectacular in the history of China's education, the new school movement which was kicked off. As a theory of change in the form of western education also since then accompany the modern school system was introduced into China. Transformed by Chinese scholars, and combined with China's national conditions and practice experiment and popularization in China, pedagogy the subject finally planted the base in China. Therefore, education is the earliest in the Chinese academy of social sciences group of independent and forming, is one of the first forum on a university course.

\section{The development of pedagogy subject}

The fundamental problem of the education theory system In general, the theoretical system of education begins with two basic problem, namely the relationship between education and social development and the relationship between education and personal development problems, although people had realized that the development of education under the control of the change of society, at the same time, in turn, to further promote social changes, but in a very long period in history, education the effect to society relative to other social factors such as economy, politics, the role of science and technology, culture and so on, has been in a relatively minor position, therefore, education has been the subject as a subject of the professional training of teachers, whose influence is mainly limited in normal education. So qualitative education discipline, is the school education teaching activities as its research object, based on the theory of psychology as its main with microcosmic research as its basic research paradigm, basically can be summarized as a what, what to teach and how to teach and learn how to learn knowledge. The change of pedagogy subject picture probably began in the 1980 s.To this period of education for the impact of the social role began emerging and is widely known, as a result, the function and value of education has been a fundamental change.

The significance of the education on socialization Due to the development of modernization, especially the generation of the knowledge economy shows the importance of knowledge and knowledge, the original seem insignificant education career, in social life under the intervention of state power has made great development, and is becoming more and more popular. In this case, the education of the meaning of social evolution is prominent and important, any country, any decision makers could not ignore the education in society in the process of the modernization of the huge role in promoting. Many education problems, meanwhile, began to have a and macro social economic, politics, science and technology, culture, etc., is closely related to the properties of the resulting new 
problems for a class of different, macroscopic education research gradually developed into an important research paradigm of education. This kind of education research to the contemporary education problems in history and social view of macroscopic, this new research field of vision is not only means education research to expand the boundaries of time and space, is also the deepening of social history. Macro graduate student education has become a new and different from the traditional microcosmic education research in the education research paradigm, regardless of its concerns, the use of words, or the required academic horizons, research methods, all has the very big difference with the traditional microcosmic education research. Different people from different disciplines to observe education problems, use different words to reveal the problems behind the phenomenon of education, about the different understanding of the education problems, formed the education research a new way of thinking. This new weather make education policy begin to enter people's horizons, and thus form an independent research field with characteristics of subject.

The characteristics of the modern discipline In general, the modern discipline has the following characteristics: one is the modern social needs as disciplines evolution and development of the power, subject classification standard is mainly determined by the nature of the research problem and practical purpose. Subject research method is divided into the decisive role of drop, if there is a unique object of study, unique research, methodology and rigorous theoretical system, not independent or mature or not necessary and sufficient condition of the modern discipline and flags. The second is the modern subject to significant social problems and comprehensive topic as the research object. Comprehensive problem research subject status, named as "discipline". Such as edge discipline with various scientific cross area as the research object, cross sectional subject to different areas of a certain common features or aspects as the research object, comprehensive discipline. Put together a variety of different disciplines, forming a new subject of organic unity. Three is the modern discipline is given priority to with applied science, wide application of multidisciplinary theory and method to study and solve problems, and derived the knowledge of application technology system; discipline within it is difficult to form a tight and uniform theoretical system. Four is the modern discipline in multidisciplinary, interdisciplinary research and cross research as the main research method, not exclusive administered to their own unique research method.

The status of the current higher education. Current our country's higher education as the secondary discipline still belongs to the education, higher education at the beginning of the creation, also appears to be in a certain extent, to imitate the related theories of pedagogy and teaching material system. But this does not mean that higher education is derived from the pedagogy. Under the current academic management system, the primary development of higher education as a discipline is able to get the space, the first thing to get education academic group accepted and approved, the second to the state, the subject system, achieve social organizational system of "this is essential choice of the management system to adapt to the current science.

\section{The basic direction of the higher education discipline construction}

After the reform and opening up In the late $1970 \mathrm{~s}$, our country enters the new period of reform and opening up, the cause of higher education also began to the healthy development track. A batch of education in this historical background, the theoretical workers and practical workers, time to promoting research of higher education, establish higher education discipline, and put into practice. From 1978 to 1984, is an important stage of our country's higher education discipline construction, whether the establishment of research institutions, organizations, or the publication of the book, all for the subject construction and development of later laid a foundation. Since the $1990 \mathrm{~s}$, discipline construction has entered a steady development period, not only has many breakthroughs in theory construction, on the study of a large number of practical problems, has made remarkable achievements, many achievements for the decision-making department attaches great importance to and adopted, the higher education reform and development had a significant positive impact. Now, our country is not only a large number of undergraduate students in higher education, and is a new "higher education research superpower". As a special research field and a discipline, of higher 
education research in China starts late, but now it has become me most countries most active in the science of education, research institutions, research team is the largest areas.

The achievement and shortage of discipline construction For more than 20 years, our country's higher education discipline construction have made many achievements, walk in front of the western countries. In the western countries, higher education research has long been seen as "problem research", has not formed the independent subjects in higher education, while higher education research in our country attaches great importance to the system research "in the form of subject research", has obvious subject to. This is our characteristic, also is our advantage. But should also see, our higher education research overall level is not high, the basic theory research is still relatively weak, discipline theory system has not been formed, the quality of personnel training also needs to improve, should be further perfect, the domestic condition of subject construction has not yet formed the international conditions.

The continuous improvement of the theory In the process of strengthening the construction of theory gradually establish and perfect the theory system of higher education Since the establishment of subject, published a lot of knowledge or teaching system in higher education discipline in the form of monographs, to play a positive role in the development of higher education enterprise. But, along with the development of the cause of higher education, with knowledge or in the form of higher education teaching material system already cannot adapt to the needs of the situation, the practical requirement of higher education to establish its own theoretical system, thus to put forward more standing in the front row in the development of higher education theory, the more effectively guide the practice of higher education. In enlarging the scale of higher education discipline graduate admissions at the same time, continuously improve the quality of graduate education, higher education discipline construction in the 21st century to cultivate enough high quality talents.

Practice and development Continue to provide quality services for the reform of higher education practice, the theory with practice in the process of the subject construction and development Since the establishment of higher education discipline, higher education research in general has developed along two lines: focusing on the establishment of a discipline, build discipline system of theoretical research; To reform the actual problems in the research for the application of key research. The discipline construction in different periods, two research emphasis. At the beginning of the 21st century, due to the need of the development of higher education and discipline construction, theoretical research and applied research objectively shows the trend of crossover and integration, more reflect the regularity of subject construction. Continues to have a foothold domestic, face the world, and make the higher education research towards the world, to create a better for higher education discipline construction of domestic and international conditions.

\section{The historical mission of higher education discipline construction}

The specialization and systematization of higher education Through to the light and so on specialized system research in the field of education, further enrich and perfect the human and the general law of understanding and the understanding of education phenomenon, thus for education to make due contributions to the construction of the basic theoretical system. From the point of view of higher education, how to fix on the traditional definition of the concept of "education", so as to make it more comprehensive, more objectively reflect the essence of education, is an imminent task. The responsibility of the higher education research. People not only expect it to clarify the law of higher education, but also expect it to show how to engage in higher education in reality, because from law to practice in the field of society is much more complicated than natural field. So higher education research is a kind of reasonable research, higher education is a kind of contact value science and scientific independent science.

Specific areas of knowledge Based on the practical, the specific field of higher education on the basis of the rational knowledge of basic principles of education, in the process of thinking from abstract to concrete, established by involving the concept and principle of higher education of higher education discipline and its theory structure, to achieve higher education practice guidance. "Higher 
education" is a special case of the "education" category, in the study of higher education, higher education will inevitably encounter all sorts of new stipulation (special).Need a specialized higher education system, in order to show the subject itself to "personality", and on the basis of the formation of the concept of higher education system and the principle of the system (including) with other common and special education subject, complete knowledge of the special phenomenon of higher education.

Modern teaching theory and method based on its national conditions The current situation of cultural tradition and national conditions in China, based on the practice of higher education reform in our country, while fully draw lessons from foreign experiences and lessons from the higher education discipline construction and theoretical research results at the same time, committed to building socialism with Chinese characteristics of higher education. In the higher education in the multidisciplinary research and investigate, it is necessary to institute involves basic concepts To clarify, build a multi-disciplinary collaboration platform; Build platform include setting up a variety of institutions and relations, create an interdisciplinary multidisciplinary cooperation team, establish a flexible research center and virtual cooperative research institutions etc.

\section{Summary}

Higher education as a universal phenomenon, have considerable universality or in common. "Mountain, can offend jade". On foreign higher education scientific analysis and comparison of research achievements of foreign higher education scientific reference and "transplant", this should be our socialist higher education an important component part of discipline construction. It can make us to avoid some unnecessary "rework" or "understanding detour", helps us to stand at the height of the world of higher education to make more comprehensive and more profound understanding, especially in the understanding of the principle of the higher education internal aspects.

\section{Acknowledgments}

This paper was supported by the decision research of provincial government bidding projects. Project name: “The main problem and analysis of open strategy in Henan Province”, project number: 2013B250

\section{References}

[1] Pan Mao-yuan, Multidisciplinary perspective of higher education research [M] (in Chinese). Shanghai, Shanghai Education Press.2001, 4.

[2] Li Ming-zhong, The study of higher education in China and learn [J] (in Chinese). Higher teaching Education research.2005 (10).

[3] Chen We, Higher education evaluation of multidisciplinary research and beyond [J] (in Chinese). Higher education research. 2003(7).

[4] Gale, T. Critical policy sociology: historiography, archaeology and genealogy as methods of policy analysis [J]. Education Policy, 2001 ( 5) 16.

[5]B.Bok, Beyond the Ivory Tower .Cambridge, Mass: Harvard University Press, 1982.

[6]Philip G.Altbachand David H.Kelly: Higher Education International Perspective: A Survey and Bibliography, Mansell Publishing Limited 1985. 